\title{
Coleções Contemporâneas do Vestuário: estudo analítico em 5 empresas da Cadeia Têxtil e de Confecções de Pernambuco
}

\section{Contemporary clothing collection: analytical study of 5 companies from the Textile and Clothing Chain in Pernambuco}

\author{
Beatriz Cavalcante Cabral de Souza e Danielle Silva Simões-Borgiani ${ }^{1 *}$
}

\begin{abstract}
RESUMO
Esta pesquisa apresenta a análise de coleções de vestuário em cinco empresas na Cidade de Caruaru, integrantes da Cadeia Têxtil e de Confecções de Pernambuco à luz da literatura. A princípio foi realizada a revisão da literatura, a fim de catalogar as definições para coleções do vestuário. Na revisão de literatura, elencaram-se os seguintes autores: Treptow (2013), Jones (2011), Mendes (2010), Navalon (2008), Rech (2002, 2003, 2006, 2012). Frings (2012), Simões-Borgiani (2014, 2016). Em seguida, foi elaborado um instrumento de análise e selecionadas cinco empresas para o estudo aplicado. O resultado da análise apresenta que as empresas estudadas, em sua maioria, têm desenvolvido coleções mix, sem harmonia estética entre peças, o que corrobora as definições de coleções contemporâneas do vestuário de SimõesBorgiani $(2014,2016)$ e que também ocorre comumente em grandes marcas nacionais e internacionais. Ainda se apresenta, nos resultados, a possibilidade de flexibilidade entre coleções, uma vez que a empresa deverá decidir o melhor tipo em relação a sua estratégia mercadológica.
\end{abstract}

Palavras-chave: Coleções do vestuário; Coleção-unidade; Coleção-mix.

\begin{abstract}
This research presents an analysis of clothing collection of 5 companies from Caruaru City, where belongs to the Textile and Confection Chain from Pernambuco, by the literature. Initially, it was carried out a literature review in order to catalogue the definitions of clothing collection. In the perspective of the literature, appended to the following authors: Treptow (2013), Jones (2011), Mendes (2010), Navalon (2008), Rech (2002, 2003, 2006, 2012). Frings(2012), Simões-Borgiani (2014, 2016). Subsequently, it was elaborated an instrument of analysis and selected 5 companies to the applied study. The results of the analysis shows that the companies studied, in its majority have developed collection-mix, without aesthetic harmony among the pieces, which corroborates with the definitions of contemporary clothing collection of Simões-Borgiani $(2014,2016)$, and which also frequently occurs in major brands-national and international. Moreover, it was exposed in the results the possibility of flexibility between the types of clothing collection, once that the company must decide the better type according to its business strategy.
\end{abstract}

Keywords: Clothing collections; Collection-unit; Collection-mix.

\footnotetext{
${ }^{1}$ UFPE-Universidade Federal de Pernambuco.

*E-mail: beatriz.cavalcante.cabral@gmail.com
} 


\section{INTRODUÇÃO}

A moda apresenta importância de caráter mundial, uma vez que é responsável por uma significativa parcela da economia. Diante disso, o profissional deve agregar qualidade de criação à qualidade produtiva, de acordo com as exigências de mercado, com flexibilidade e rapidez de resposta (RUTSCHILING \& BROEGA, 2009).

Para Carvalhal (2016), as marcas de moda e, consequentemente, seus produtos devem ter propósito de continuidade nesse mercado cada vez mais exigente e consciente.

Embora a moda permeie muito mais que produtos, por ser um fenômeno socioeconômico e cultural (CRANE, 2011), este estudo se propõe a investigar coleções contemporâneas do vestuário de produtos de moda, destinadas ao vestuário casual de massa.

Tratando-se de coleções contemporâneas do vestuário, Simões-Borgiani (2014, 2015) apresenta duas terminologias como classificação para possíveis coleções quanto à estética. São elas: coleção-unidade e coleção-mix.

Entende-se que coleção-unidade é aquela que tem expressiva harmonia estética entre os produtos, ou seja, vários elementos se repetem para fortalecer o conceito ou tema proposto. Podem ser repetições de estampas, formas, cores, silhuetas, entre outros princípios de design (SIMÕES-BORGIANI, 2014). Essa definição é corroborada por Treptow (2013), Jones (2011), Mendes (2010), Navalon (2008) e Rech (2002, 2003, 2006, 2012) os quais apresentam métodos ou reflexões sobre coleções com ênfase na unidade visual estética.

Nas reflexões de Simões-Borgiani (2014), destaca-se a terminologia de coleçãomix, defendida como estratégica para adequação ao mercado contemporâneo: é uma coleção que apresenta vários estilos, diversidade de cores, formas, silhuetas. São coleções bem diversificadas que não se enquadram nas definições anteriores para coleções do vestuário e que, apesar de não estarem citadas na literatura anterior ao estudo, estão sendo amplamente desenvolvidas por marcas de diversos portes e têm se mostrado bem assertiva do ponto de vista de vendas.

A partir dessas reflexões, definiu-se o local de estudo/observação da Cadeia Têxtil e de confecções de Pernambuco - Cadeia T\&C-PE, localizado no interior de Pernambuco, composto pelas cidades de Agrestina, Brejo da Madre de Deus, Caruaru, Cupira, Riacho das Almas, Santa Cruz do Capibaribe, Surubim, Taquaritinga do Norte, Toritama e 
Vertentes. Esta Cadeia tem característica econômica baseada na confecção de peças do vestuário. As empresas desta Cadeia, segundo estimativas do SEBRAE-PE (2012), produzem cerca de 4.318 peças ao mês; as facções cerca de $3.124 /$ mês, e seu faturamento em 2011 chegou a 1,1 bilhões de reais. Como recorte deste universo, foram escolhidas cinco empresas localizadas em Caruaru para realização deste estudo.

A análise aqui apresentada visou a responder à pergunta de pesquisa "Qual tipo de coleção de vestuário vem sendo produzido em algumas empresas do vestuário de Caruaru?"

Diante disso, este estudo analisa e caracteriza algumas coleções do vestuário produzidas na Cadeia T\&C-PE de acordo com as terminologias propostas por SimõesBorgiani (2014), a fim de contribuir com a análise e debate em torno de que tipos de coleção vem sendo praticado para moda em massa em Caruaru.

Este estudo de coleções contemporâneas do vestuário fomenta reflexões acerca do tema, assunto este que deve ser mais debatido, pois o consumidor contemporâneo é caracterizado por uma diversidade de gostos e estilos, tendo em vista também que já há uma nova visão do que são coleções e de como elas devem ser bem planejadas para o sucesso mercadológico delas.

Assim, estudar as características das coleções do vestuário em cinco empresas de Caruaru é relevante para fazer o mapeamento dos tipos de coleções que são produzidas nesse espaço. Dessa maneira, tenta-se implementar uma nova visão de como se planejar coleções nesse contexto, que deve ser um planejamento com visão mercadológica e estratégia, refletindo que o mercado é o guia para implementação de novas visões estratégicas de venda.

A proposta deste estudo é, também, ampliar a divulgação para a academia sobre a existência de mais de uma definição em relação às características de coleção do vestuário, que vai depender do cenário mercadológico em que a empresa está inserida, podendo até realizar mais de um tipo de coleção.

O tema planejamento e desenvolvimento de coleções deve ser constantemente investigado, a fim de que sempre se construam diretrizes contextualizadas para que tal planejamento norteie resultados melhores para as empresas. Considerando ainda a quantidade de empregos gerados na área e significativos números na cadeia têxtil e de confecções, é preciso entender este setor como um dos fatores do desenvolvimento de Pernambuco e, por isso, a necessidade de sempre buscar melhorias para ele. É uma 
justificativa mercadológica e de estratégia que atinge diretamente os produtores e confecções, bem como contribui para novos debates na academia.

\section{Metodologia}

Classificação da pesquisa

Nesta Pesquisa, a classificação quanto à natureza é de pesquisa aplicada, pois pretende gerar conhecimento sobre coleções do vestuário confeccionados na Cadeia T\&C-PE, para posterior estudo de gestão estratégica dessas coleções. De acordo com Silva \& Menezes (2005), a pesquisa aplicada envolve interesses e verdades locais e visa à solução de problemas em aplicação prática, o que se aplica a esta pesquisa que pretende estudar a Cadeia T\&C-PE que detém parcela significativa do PIB Pernambucano. Empregando grande parte da população desta região, como problema prático estudaremos qual perfil de coleção mais se adéqua à realidade da Cadeia T\&C-PE, de acordo com as terminologias propostas por Simões-Borgiani (2014).

Quanto à abordagem, será uma pesquisa quali-quantitativa, visando a classificar as coleções em coleção-mix ou coleção-unidade, através de levantamento de dados colhidos em cinco empresas. Através da análise quantitativa do total de peças para cada coleção e o número de estilos repetidos ou não, foi feita uma análise proporcional para assim classificá-la em coleção-mix ou coleção-unidade.

Quanto aos objetivos, esta pesquisa se classifica em pesquisa descritiva por descrever as características de certa população (SILVA \& MENEZES, 2005), neste caso, coleções do vestuário produzidas pela Cadeia T\&C-PE, através de levantamento e observação sistemática dessas coleções

Os procedimentos técnicos foram de pesquisa bibliográfica e documental em estudo de caso. Para a pesquisa documental foram escolhidas cinco empresas e suas respectivas coleções. Segundo Silva \& Menezes (2005), a pesquisa documental trata analiticamente de materiais - como fotografia neste caso - que ainda não receberam tratamento analítico.

Locus - Cadeia Têxtil e de confecções de Pernambuco

A Cadeia T\&C-PE é composta hoje por dez cidades do Estado de Pernambuco, de acordo com o estudo realizado pelo (SEBRAE-PE, 2012). São elas: Agrestina, Brejo da Madre de Deus, Caruru, Cupira, Riacho das Almas, Santa Cruz do Capibaribe, Surubim, Taquaritinga do Norte, Toritama e Vertentes. Caruaru, Santa Cruz do Capibaribe e 
Toritama são as cidades que detêm maior destaque dentre os dez municípios, e os motivos são o fato de as três cidades juntas possuírem $77 \%$ do total do produto interno Bruto da Cadeia T\&C-PE. Entre as dez cidades, o PIB é de R $\$ 8$ bilhões, sendo que esse número é $5 \%$ do PIB pernambucano e cresceu 1,5 mais que o PIB nacional. Esta população cresceu 2,2 vezes mais que a população do Brasil entre 2000 e 2010 (SEBRAE-PE, 2012).

Dentre as três cidades mais fortes da Cadeia T\&C-PE, Santa Cruz do Capibaribe e Toritama, cada uma delas realiza semanalmente a Feira da Sulanca (grande feira ao ar livre que comercializa, dentre outras coisas, principalmente produtos do vestuário), e esses três municípios possuem $66 \%$ do total da população dos 10 municípios (nas 10 cidades são 667 mil habitantes). Além, ainda, de haver grandes centros de comercialização atacadistas nessas cidades: o Parque das Feiras em Toritama, o Polo Comercial em Caruaru e o Moda Center Santa Cruz, e este último é considerado o maior centro de compras atacadistas da América Latina, contendo 9.624 boxes e 707 lojas e estacionamento para quatro mil carros. Nas altas temporadas de venda, chega a receber cerca de 100 mil clientes vindos de todo Brasil; as cidades de Santa Cruz do Capibaribe e Toritama têm praticamente toda a economia baseada na confecção e atividades correlatas (SEBRAE-PE, 2012).

Além disso, há em torno de 100 mil pessoas envolvidas na indústria confeccionista nas 10 cidades, embora a maioria dos empregos seja informal. Todavia, comparando-se com a indústria pernambucana que ocupa cerca de 200 mil pessoas, isso é metade do contingente total do estado. Somado a isto, o faturamento da Cadeia T\&CPE anualmente chega a $\mathrm{R} \$ 1$ bilhão e emprega 130 mil pessoas no total (trabalhadores da indústria, setor de vendas etc.). A média de salário dos trabalhadores é de um pouco mais que um salário-mínimo, tanto nas empresas como nos empreendimentos complementares ou facções, e a jornada de trabalho aproxima-se a 40 horas semanais para os vários setores: comercialização, produção, confecção e mão de obra (SEBRAE-PE, 2012).

Nos dez municípios considerados parte da Cadeia T\&C-PE, há uma estimativa de que haja 18.803 unidades produtivas entre empresas e facções, onde a informalidade é maior nos empreendimentos complementares, cerca de 93\% do total dos empreendimentos complementares e $66 \%$ das empresas. Percebe-se que a maioria é micro e pequenos empreendimentos; assim como a maioria dos empregos, a informalidade contribui para os baixos preços praticados (SEBRAE-PE, 2012). 
Em termos de contratação de terceirizados, na Cadeia T\&C-PE acontece por proporcionar vantagens sendo elas: isentar o empresário de responsabilidades em relação aos trabalhadores, custos adicionais, como encargos sociais, aluguéis e, caso o empresário queira aumentar sua produtividade, não há preocupação com aumento de estrutura, pois tudo isso fica a critério da administração dos empreendimentos complementares (SEBRAE-PE, 2012).

Simões (2010) ressalta que, dentre as produções da Cadeia T\&C, há o predomínio de produção de malharia, surfwear, moda praia, lingerie, jeans e modinha (moda casual) e a mão-de-obra tem característica familiar.

Instrumento de Análise

Para a parte analítica da pesquisa, percebeu-se a necessidade de desenvolver um instrumento de análise. Baseando-se nos principais elementos de criação do design explanados por Jones (2011) que são: silhueta, linha, textura e formas, junto aos exemplos demonstrados por Leite \& Velloso (2014): desenhos técnicos que demonstram em detalhes como seriam esses princípios aplicados às roupas, através de modelos básicos de como a roupa é estruturada que, juntos aos princípios de criação, possibilitam inúmeras quantidades de modelos. Frings (2012) explica que esses elementos de design (cor, tecido, linha e forma) fazem parte de um bom design e ajudam o profissional na hora da criação, assim também define a autora que os usos desses elementos são inconscientes e não intencionais “O designer não pensa nesses elementos conscientemente, seu uso se torna natural" (FRINGS, 2012, p.220).

Desta maneira, juntando as perspectivas desses autores e utilizando como base principal os desenhos técnicos de Leite \& Velloso (2014), foi elaborado o instrumento de análise. Estas autoras caracterizam por regiões, onde podem ser aplicados os elementos de design. São eles: região da cava, do busto, da cintura e do quadril. Portanto, é assim que as autoras delimitam o que fica em cada região:

1. Região da cava: situada acima da linha da cava, contém os traçados do decote, do ombro e de cava.

2. Região do busto: situada entre a linha da cava e uma linha abaixo do busto, pode conter as pences ou os recortes modeladores do busto.

3. Região da cintura: situada abaixo da região do busto, contém a pence modeladora da cintura, que pode se encontrar com a pence modeladora do busto.

4. Região do quadril: situada abaixo da cintura, descendo em direção à coxa. É a região mais larga do corpo, onde se localiza a altura do gancho para a construção da calça (LEITE \& VELLOSO, 2014, p. 40). 
Por isso, os elementos constituintes da tabela foram silhuetas: a forma geral da peça, comprimentos: os limites das peças e de parte das peças, como vestidos, saias e mangas, decotes: são os formatos aplicados na região do colo, mangas que são responsáveis por vestir o braço, recortes, golas que são aplicações na cava e ainda foram acrescentados os detalhes que podem ser aviamentos, fechamentos, acessórios e amarrações, segundo exemplos básicos demonstrados por Leite e Velloso (2014) e que constituem as aplicações feitas nas regiões básicas do corpo.

Além desses parâmetros, foram acrescentados os critérios de cor e estampa. Sendo assim, a cor, ressalta Frings (2012), é a primeira sensação que o consumidor percebe em uma peça do vestuário. Porém os parâmetros para estampas foram utilizados as categorias de estampa descritas por Briggs-Goode (2014), que são:

1. Floral: estampas que retratam flores e plantas.

2. Geométricos: com imagens de figuras geométricas e não-orgânicas.

3. Étnico: com imagens referentes a grupos antropológicos.

4. Figurativos: representam imagens únicas.

Dessa forma, a figura 3 representa o instrumento de análise desenvolvido para esta pesquisa. Os parâmetros são detalhes, golas e comprimentos disponibilizados na ficha conforme seu surgimento ao longo da coleção, uma vez que há uma grande disponibilidade de modelos que não comportaria em uma ficha.

Figura 1-Ficha de análise das coleções.

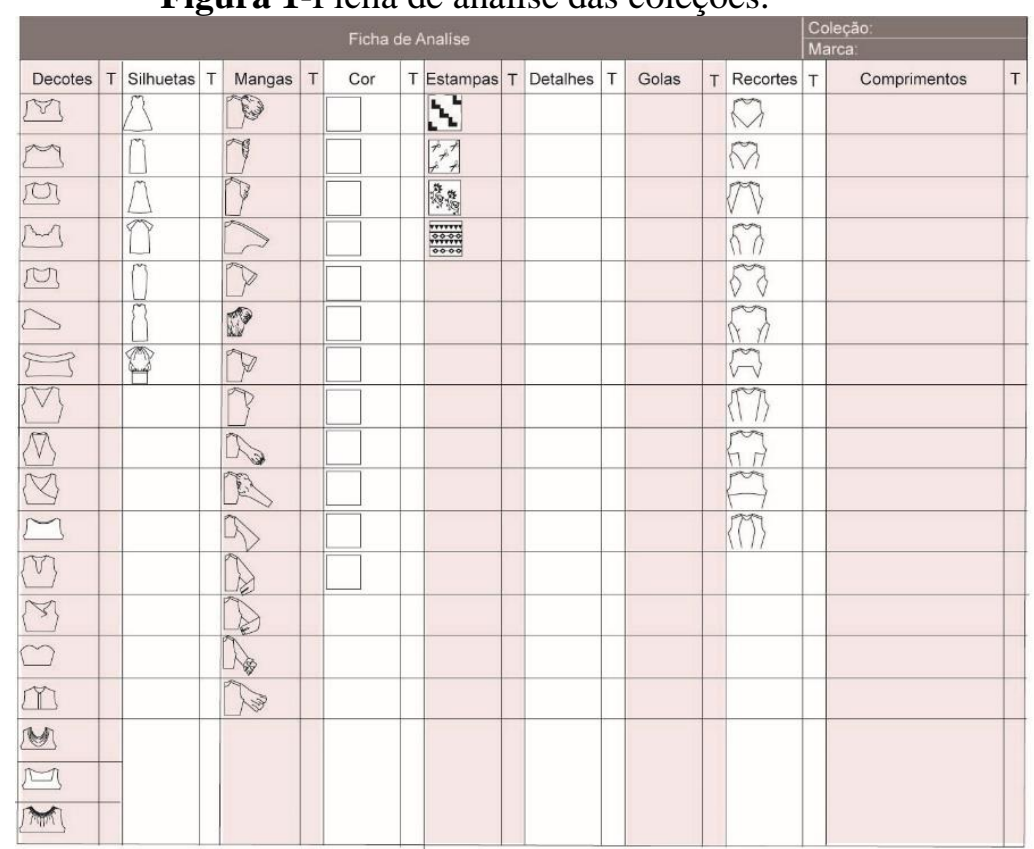

Fonte: elaborado pela autora baseado em Briggs-Goode(2014), Frings (2012) e Leite e Velloso (2014). 


\section{Coleções Contemporâneas do Vestuário}

A primeira coleção de moda, concebida por Charles Worth, apresentava modelos distintos agrupados pela sazonalidade. Worth foi um costureiro do Século XIX com grande contribuição no desenvolvimento de coleções. É considerado o pai da alta costura, abriu a primeira Maison e produziu mais inovações, como instituir a profissão modelo, desfiles de moda e lançamento de coleções (COSGRAVE, 2012; LAVER, 2002).

Worth concebia peças estratégicas para sua clientela, pensando exatamente em cada uma delas, considerando o que gostavam e preferências para colocar como detalhes nas peças. Além desse olhar minucioso no cliente final, a forma de apresentar as peças em desfiles também tinha muita atenção ao cliente, uma vez que as modelos escaladas tinham o mesmo biotipo e aparência similar às clientes-alvo (COSGRAVE, 2012).

Com esses achados históricos, pode-se refletir que a primeira coleção de moda da história foi uma coleção de peças específicas para cada cliente em potencial e que apresentavam unidade apenas pela sazonalidade, uma vez que a unidade estética não estava presente, à medida que Worth concebeu modelos para perfis bem distintos. Acresce-se ainda a reflexão que a coleção de Worth foi uma estratégia de mercado para vender produtos de forma diferente da que acontecia à época.

O conceito de coleções do vestuário foi se moldando com o tempo e sendo difundido de outras formas, com o amadurecimento do fazer e mudanças do mercado de moda.

Na visão de Jones (2011), as coleções refletem “o espírito do tempo”, através do uso de cores, formas, texturas, padronagens, silhuetas e tendências escolhidos pelo designer que as desenvolveu. É reforçado que a coleção deve manter o equilíbrio entre os itens citados, para a coleção não ficar desordenada.

Ao realizar uma revisão na literatura sobre coleções do vestuário, encontram-se diversos autores que versam que as coleções devem ter harmonia estética e unidade.

Treptow (2013) afirma que coleção é um conjunto de peças projetadas para uma estação, seguindo uma tendência e que possui harmonia entre si (elementos de estilo, cores e formas). Mendes (2010) corrobora esta definição, quando diz que:

[uma coleção] é o conjunto de peças do vestuário apresentadas ao público com dois objetivos bastante distintos: lançamento para estabelecer tendências ou para disponibilizar produtos no mercado. Em qualquer dos casos, a coleção tem que apresentar looks harmônicos quanto ao seu conjunto (MENDES, 2010, p. 134). 
Percebe-se que a definição de Mendes (2010) corrobora Jones (2011) e Treptow (2013). Todos enfatizam harmonia dos produtos em congruência também com Rech (2002, 2003, 2006 e 2012) que define coleção como conjunto de produtos harmônicos do ponto de vista visual ou comercial, com fabricação e entrega para determinada época do ano.

Sendo mais um autor que defende a coleção com imagem coesa, Frings (2012) versa sobre a importância de tema bem desenvolvido e imagem dando unidade à coleção para facilitar a comercialização dos produtos. Mas, também diz que a coleção pode ser única em estética/estilo ou possuir pequenos grupos internos de estética harmônica/similar, mas diferente esteticamente de outros grupos na mesma coleção.

Ampliando essas terminologias e propondo classificação diferente para coleções contemporâneas, Simões-Borgiani (2014) identificou e classificou as coleções em dois tipos quanto à estética: coleção-unidade e coleção-mix.

Segundo Simões-Borgiani (2014) a coleção-unidade é aquele em que as peças têm harmonia estética através de estilo definido, tema ou conceito, estação a que se destinam, formas, cores e padrões. Já a coleção-mix, apresenta vários estilos, silhuetas, cores e formas, na mesma coleção. As peças entre si parecem não ter nenhuma relação tão pouco ser da mesma coleção. Simões-Borgiani (2014) complementa que coleção mix está sendo desenvolvida recorrentemente por empresas de diversos portes, por apresentar-se como uma estratégia de mercado contemporâneo (figura 2).

Figura 2: Fotos da coleção Fall 2021 ready-to-wear

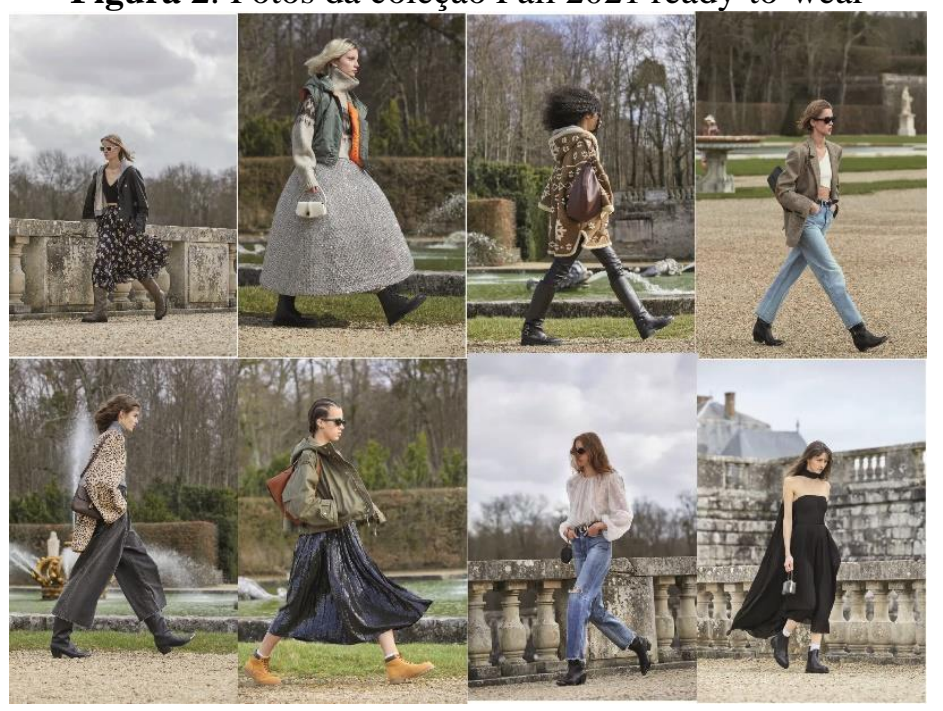

Fonte: Vogue (2021) 
Projetar uma coleção está intimamente ligado ao público-alvo a que a coleção se destina, explica Renfrew e Renfrew (2010). Por isso, o mercado de moda divide-se em diferentes níveis e tipos: cada mercado possui seu público e maneiras de desenvolver suas coleções. São eles "alta-costura e alfaiataria sob medida, prêt-à-porter, grifes de estilistas, marcas de luxo, cadeia de loja ou mercado de massa, e compras por catálogo" (RENFREW E RENFREW, 2010, p.79).

No campo geral do design Best (2012) explica que projetos de design se inserem em contextos específicos, estes com particularidades e oportunidades. Cabe ao profissional de design apresentar novas soluções para problemas vigentes. Os usuários devem ser estudados e bem compreendidos assim como os meios de produção, para que se tome soluções adequadas tantos para os consumidores como para os fabricantes.

Best (2012) expõe a necessidade que o designer nos mais diversos campos de atuação tem de conhecer modos de produção antigos e atuais, aquilo que obteve um bom retorno comercial ou não, para que assim proponha-se soluções completamente novas ou apenas modificações de normas pré-estabelecidas como "certas". O que se vê nas divergências entre os projetos de coleção-unidade e as coleções-mix, para a academia as coleções consideradas ideais, de acordo com as bibliografias indicadas nas disciplinas de projeto de coleções são as coleções-unidade, mas o que se é constado é que nem sempre esse tipo de coleção é a unicamente desenvolvida e bem absorvida pelo mercado na prática.

Apesar de já se constatar as coleções-mix em mercado de luxo, grandes grifes e cadeias de loja, no recorte deste estudo delimitou-se ao mercado popular de massa.

\section{Resultados e discussões}

Foram analisadas cinco empresas e oito coleções no total. Os nomes das empresas foram omitidos, sendo substituídos por números de 1 a 5 , para cada uma das estudadas.

Na marca 1, de moda feminina, foram analisadas 2 coleções: inverno 2018 (Figura 04) e verão 2018, ambas apresentavam uma grande variedade de estilos. A coleção inverno 2018 tinha 9 variedades de decotes, 3 tipos de silhuetas, 5 tipos de mangas, 15 variações de cores, 4 tipos de estampas, 4 tipos de detalhes, 5 tipos de golas, 2 tipos de recortes e 14 tipos de comprimentos. Houve predominância de estampas geométricas em um total de 80 peças da coleção. Já na coleção verão 2018, notou-se 10 tipos de decotes, 5 silhuetas, 9 mangas, 14 variações de cores, 4 tipos de estampas, 3 tipos de detalhes, 2 
tipos de golas e 14 tipos de comprimentos em um total de 89 peças. Ambas as coleções podem ser classificadas como coleção-mix devido à grande diversidade de estilos, formas e detalhes propostos que causam pouca ou nenhuma unidade visual entre produtos.

Figura 3:Análise da coleção inverno, marca 12018

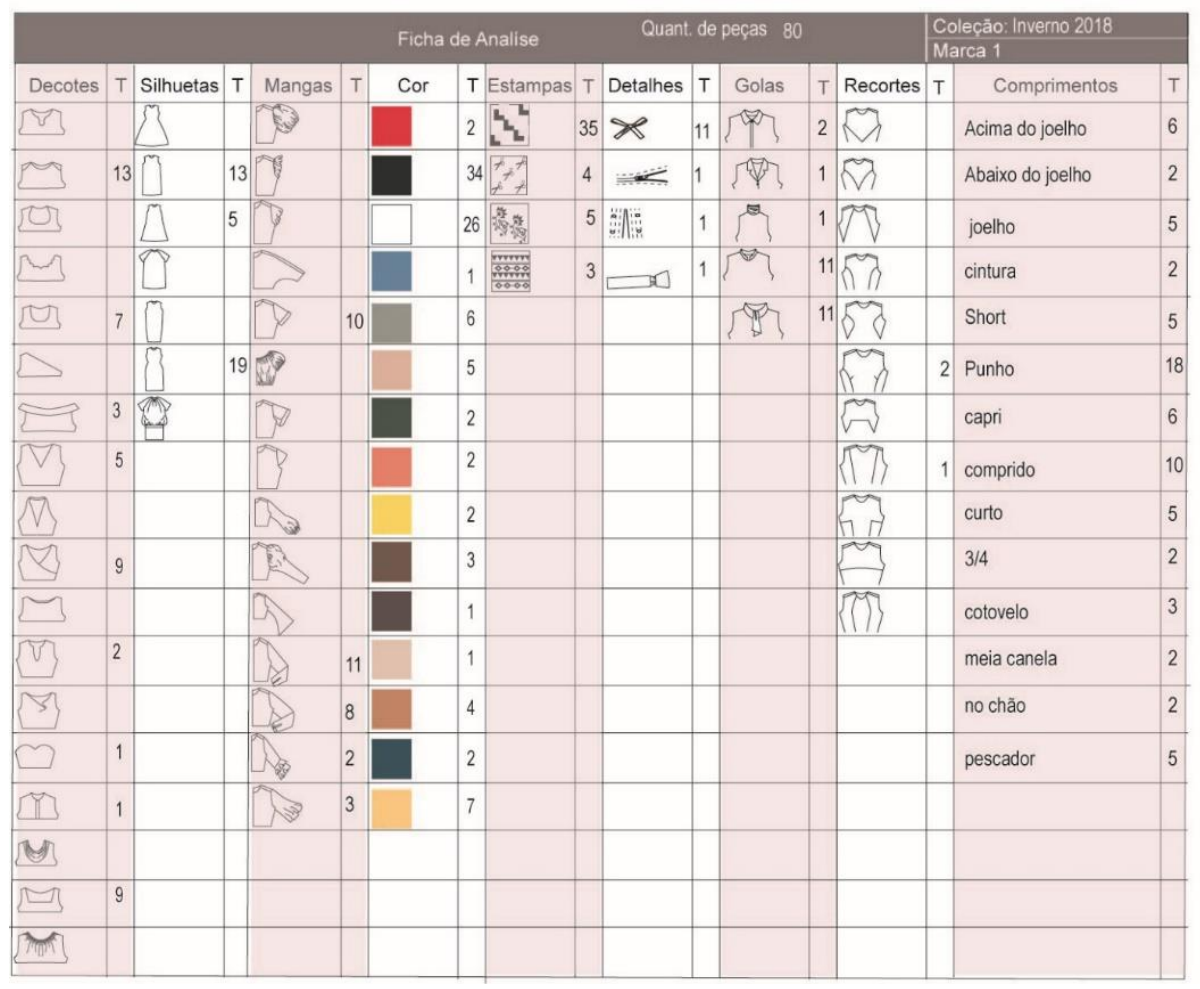

Fonte: Souza ( 2018)

Na marca 2 de moda infantil, foram analisadas 2 coleções. Na primeira coleção investigada, detectaram-se 4 variedades de silhuetas, 4 variedades de mangas, 16 cores, e 3 tipos de estampas, 4 tipos de golas, 4 tipos de comprimentos. Vale considerar que foi uma coleção pequena com apenas 13 peças e muitas variações estéticas (Figura 05). Na outra coleção, perceberam-se 3 tipos de decotes, 2 tipos de silhueta, 4 tipos de mangas, 11 cores, 3 tipos de estampas, 1 tipo de detalhe (laço), 2 tipos de golas e 5 tipos de comprimentos, no total de 11 peças. Ambas detêm uma grande variedade nas cores propostas estabelecendo assim uma coleção-mix. 
Figura 4:Análise da coleção da marca 2

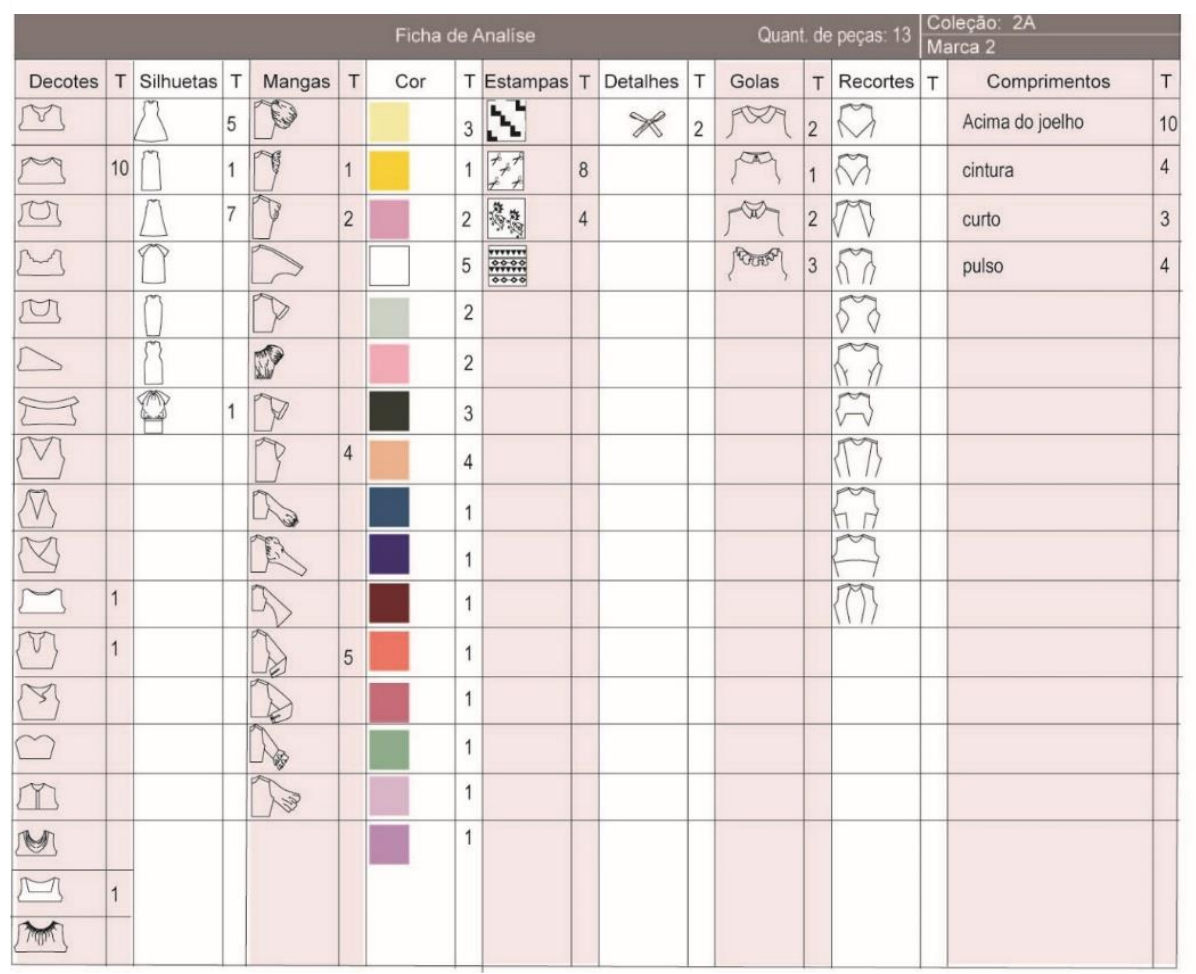

Fonte:Souza ( 2018)

Na marca 3 de vestidos infantis, foi analisada uma coleção e foram notados 7 tipos de decotes, 5 tipos de silhuetas, 3 tipos de mangas, 10 tipos de cores, 3 variedades de estampas, 2 tipos de detalhes, 2 tipos de golas, 1 tipo de recorte e 5 tipos de comprimentos em um total de 14 peças. É uma coleção heterogenia e classificada em coleção-mix.

Na Marca 4 de camisaria masculina, perceberam-se 2 tipos de decotes, 2 tipos de silhuetas, 12 cores, 1 tipo de gola, 3 tipos de recortes e 5 variedades de comprimentos, totalizando 9 peças analisadas, classificada em coleção-mix por não haver quase nenhuma repetição de elemento ou princípio de design entre as 9 peças.

As últimas coleções analisadas, da Marca 5 são a de gênero, autoral e em produção slowfashion. Uma coleção fez uso de 3 tipos de decotes, 3 tipos de silhuetas, 3 variedades de mangas, 10 cores, 2 tipos de estampas, 3 tipos de golas e 9 tipos de comprimentos. Sendo comparado com o número total de 53 de peças, não há grandes variedades de estilos havendo uma coleção homogênea ou coleção-unidade (Figura 06). Na outra coleção da mesma marca, usaram-se 1 tipo de decote, 4 tipos de silhuetas, 1 tipo de manga, 7 tipos de cores, 2 de estampas, 1 de detalhes, 2 de golas e 9 de comprimentos, 
sendo assim uma coleção uniforme em relação aos estilos propostos, ou uma coleçãounidade.

Figura 06: Análise da coleção da marca 5.

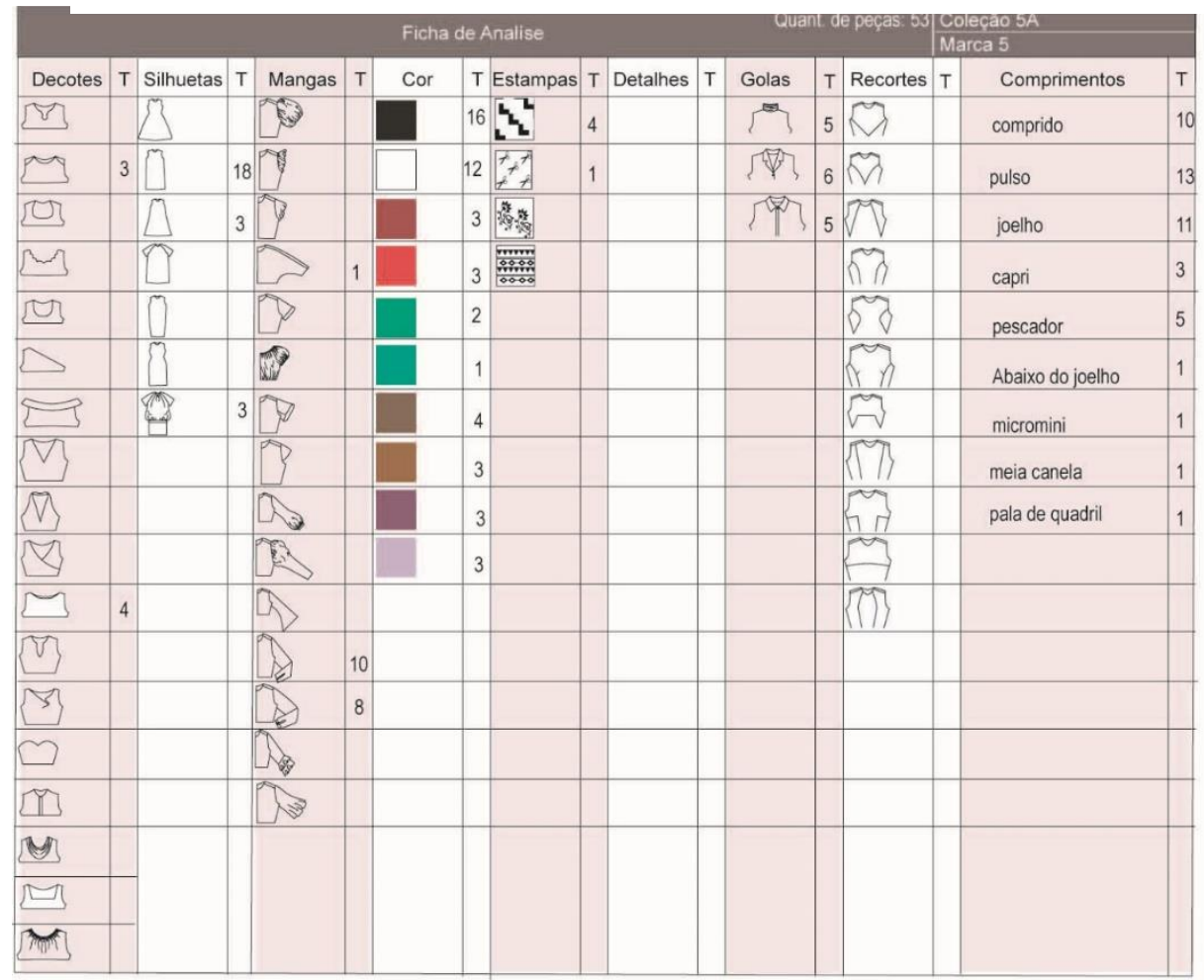

Fonte: Souza, (2018)

Percebe-se, neste recorte de cinco empresas, que a maioria delas tem desenvolvido coleções mix e reportando-se isso à constatação de Simões-Borgiani (2014) em relação ao perfil empresarial de confecções atacadistas e varejistas ou empresas que produzem coleções grandes, corroborando também os posicionamentos de Frings (2012) concernente à coleção com grupos com coleção menores. Em contrapartida, a empresa analisada que continha coleção-unidade, foi uma empresa autoral, de slowfashion, com coleção temática e com apelo comunicativo através dos produtos, logo, a coerência estética e visual foi harmônica, a fim de consolidar a mensagem proposta através dos produtos. Esse tipo de coleção é aquele que se encaixa perfeitamente nas diretrizes de Treptow (2013), Jones (2011), Mendes (2010), Navalon (2008), Rech (2002, 2003, 2006, 2012).

Cabe destacar, aqui, que alternar o tipo de coleções por empresas também é uma prática comum que vem sendo observada, embora não tenha sido recorte deste estudo. Há empresas que oscilam entre coleções unidade e mix, à medida que vão percebendo e 
atendendo as necessidades mercadológicas e estratégicas corroborando os apontamentos de Best (2012) e Simões-Borgiani \& Waechter (2021).

Desenvolver coleções do vestuário deve ser algo estratégico, extremamente planejado para que seja assertivo em relação ao que se almeja: vendas em massa ou consolidação de imagem/público restrito. E, em busca do ideal, cabe à equipe de criação, junto à de alta gestão, definir as estratégias para cada coleção. Desta forma, é possível flexibilizar, fazer coleções mix ou unidade e nenhum minimiza o outro, uma vez que cada uma apresenta seus objetivos, conforme reforça Simões-Borgiani (2014).

\section{Considerações Finais}

O objetivo geral deste estudo foi investigar e tipificar as coleções do vestuário estudadas de acordo com Simões-Borgiani (2014), sendo, no total, 8 coleções que serviram de amostra. Destas, $75 \%$ foram classificadas como coleções-mix, e $25 \%$ categorizadas como coleções-unidade. Esses dados fazem refletir que há novas maneiras de se planejar coleções e que uma não exclui a outra, sendo importante, tanto para a academia quanto para mercado, articular qual tipo de coleção se adéqua melhor ao objetivo final da marca.

Foram expostas nesta pesquisa algumas definições de coleções propostas por alguns autores. Entre as definições, algumas corroboram entre si como Treptow (2013), Jones (2011), Mendes (2010), Navalon (2008), Rech (2002, 2003, 2006, 2012), ao explanar que coleções são séries de objetos que possuem alguma semelhança, algo em comum esteticamente. Também se apresentou uma proposta distinta e mais ampla para coleção de Simões-Borgiani (2014) que tipifica as coleções em unidade ou mix. Essas definições serviram para ampliar o panorama do que pode ser coleção, uma vez que a definição de objetos com coerência estética é o mais difundido.

Para análise das coleções foi elaborado um instrumento de análise com parâmetros presentes em toda roupas. São eles: decote, silhueta, manga, cava, gola, cores, estampas, comprimentos. Esses elementos juntos tornam as possibilidades múltiplas. Esse instrumento pode ser replicado como balizador para análise de coleções, seja para manter a unidade seja para fazer um mix. Quanto mais se utiliza na diversidade de itens por colunas, bem quanto menor for a quantidade de peças da coleção, há uma tendência a se tornar coleção-mix, pois serão muitos detalhes que pouco se repetirão entre peças (silhuetas, decotes, estampas, recortes...). No sentido inverso, se há pouco uso das 
possibilidades variantes de cada coluna, haverá visualmente unidade entre as peças, uma vez que se repetirão os detalhes escolhidos como princípios e elementos de design.

Destaca-se no instrumento, uma das contribuições para o campo do design e da moda, uma vez que o mesmo pode ser utilizado como ferramenta para mensurar características, elementos e princípios de design em produtos de moda, bem como, pode ser utilizado para outras investigações.

Dentre as relevâncias deste estudo, apresenta-se um panorama de como muitas coleções contemporâneas são desenvolvidas: hoje, há cada vez mais a recorrência de coleções-mix que, por terem uma variedade muito grande de peças na mesma coleção, pode haver uma melhor captação no mercado, tanto por atingir vários consumidores, como por atender o mesmo consumidor em mais peças, e, ainda, por satisfazer a multiplicidade de estilos que caracteriza os consumidores contemporâneos. Sendo assim, o designer, tendo a visão de que existe mais de uma maneira de planejar coleções, ampliase a visão, que existe na academia, de que coleções são apenas as coleções harmônicas com unidade visual e ampla repetição de detalhes nas peças. E aproxima-se da visão de Best (2021) sobre a gestão do design e necessidade de adequações relacionando-se as experiências anteriores que deram certo ou não para propor novos produtos.

Esta pesquisa está sendo ampliada para análise de marcas importantes no cenário brasileiro e marcas internacionais reconhecidas como referências da moda, almeja-se, assim, ir revalidando esse novo tipo de coleção, diagnosticando o que acontece além do mercado local.

\section{REFERÊNCIAS}

BEST, Kathryn. Fundamentos de Gestão de design. Bookman Editora, 2012.

BRIGGS-GOODE, Amanda.Design de estamparia têxtil.Porto-Alegre : Bookman, 2014.

CARVALHAL, André. Moda com propósito: manifesto pela grande virada. Editora Paralela, 2016.

COSGRAVE, B. História da indumentária e da moda: Das antiguidades aos dias atuais. Tradução de Ana Resende. Barcelona: Gustavo Gil, 2012.

CRANE, D. A moda e seu papel social; classe, gênero e identidade das roupas. Tradução: Cristiana Coimbra, São Paulo: editora Senac São Paulo 2011. 
FRINGS, Gini Stephens.Moda: do conceito ao consumidor .[trad.] Mariana Belloli. 9. Porto Alegre: Bookman, 2012.

GONCALVES, XICO. Conheça Elsa Schiaparelli, A Costureira Surrealista. In: Blog do Xico. Disponível em: < http://xicogoncalves.com.br/conheca-elsa-schiaparelli-acostureira-surrealista/>. Acessado em: Março, 2021.

JONES, S. J. Fashion Design - manual do estilista. Tradução de Iara Biderman. São Paulo: Cosacnaify, 2011.

LAVER, J. A roupa e a moda: uma história concisa. São Paulo: Companhia das Letras, 2002.

LEITE, Adriana Sampaio e VELLOSO, Marta Delgado. Desenho técnico de roupa feminina. 3. Ed. Rio de Janeiro: Senac, 2014.

MENDES, F. D. Um estudo comparativo entre as manufaturas do vestuário de moda do Brasil e da Índia. Tese de doutorado (Doutorado em Engenharia de Produção). Universidade Estadual Paulista, São Paulo, 2010.

NAVALON, E. Design de moda: interconexões metodológicas. Dissertação de Mestrado (Mestrado em Design) Universidade Anhembi, São Paulo, 2008.

PIERI, Kerry. See Chanel`s Full Cruise 2021 Collection. In: Hapersbazaar/ Disponível em: <https://www.harpersbazaar.com/fashion/fashion-week/g32798877/chanel-cruise2021-collection/>, Acessado em: Julho, 2020.

RECH, Sandra Regina.Moda: por um fio de qualidade. Florianaópolis : UDESC, 2002. p. 133.

RECH, S. R. Conceito de Produto de Moda. Actas de Diseño, v. 13, p. 187-191, 2012.

RECH, S. R. The Fashion Design Manager: global market differentiating. (Anais...) III International Textile and Apparel Conference. Rio de Janeiro: Cetiqt, 2003 (1 Cd-rom).

RECH, S. R. Cadeia produtiva da moda: um modelo conceitual de análise da competitividade no elo confecção. Tese de doutorado (Doutorado em Engenharia de Produção). Universidade Federal de Santa Catarina. Florianópolis, 2006.

RENFREW, Elionor e RENFREW, Colin. Desenvolvendo uma coleção. [trad.] Daniela Fetzner. Porto Alegre: Bookman, 2010.

RUTSCHILING, A. A.; BROEGA, A.C. Design de vestuário de moda contemporânea: criação versus produtos. In: Colóquio de moda, 5, 2009, Anais: Recife, 2009.

SEBRAE-PE. Estudo Econômico do Arranjo Produtivo Local de Confecções do Agreste Pernambucano. Recife, 2012. 
SILVA, Edna Lúcia Da e MENEZES, Esfera Muskat. Metodologia da pesquisa e elaboração de dissertação. 4. Florianópolis: UFSC, 2005,

SIMÕES, Danielle Silva. Procedimentos metodólogicos para criação de coleções para o pólo de confecções do agrete de Pernambuco. 2010. 151 f. Dissertação (Mestrado em Design). Universidade Federal de Pernambuco, Recife, 2021.

SIMÕES-BORGIANI, Danielle Silva. Um estudo sobre as estratégias de gestão de coleção do vestuário em seis empresas de Pernambuco. 2014. Tese (Doutorado em Design). Universidade Federal de Pernambuco, Recife, 2021.

SIMÕES-BORGIANI, Danielle Silva. Reflexões sobre coleções do vestuário e proposição de terminologia: coleção-unidade e coleção-mix. In: Congresso Brasileiro de Iniciação Científica em Design e Moda, 2. 2015.

SIMÕES-BORGIANI, Danielle Silva. Reflexões sobre a classificação de coleções do vestuário: coleções-unidade e coleções-mix. Modapalavra E-periódico, v. 9, p. 237 $249,2016$.

SIMÕES-BORGIANI, Danielle Silva; WAECHTER, Hans da Nóbrega. Strategies to design clothing collections using a management perspective: a proposition of guidelines International Journal of Development Research, v. 11, p. 46601-46603, 2021

SOUZA, Beatriz Cavalcante Cabral. Um estudo sobre coleções contemporâneas do vestuário. 2018. Trabalho de Conclusão de Curso (Bacharelado em Design). Universidade Federal de Pernambuco, Caruaru, 2021.

TREPTOW, D. Inventando moda: Planejamento de coleções. 3 ed. Brusque: do autor, 2013. 